\title{
How do Teachers' Gender Stereotypes Impact Students?
}

\author{
Anqi Dai ${ }^{1, \dagger}$, Danni $\mathrm{Li}^{2, \dagger}$, Hongxu Zhu ${ }^{3, *},{ }^{*}$, Zihan Zhang ${ }^{4, \dagger}$ \\ ${ }^{1}$ Yangzhou University, Suzhou, Jiangsu, China \\ ${ }^{2}$ Hunan International Economics University, Hunan, Changsha, China \\ ${ }^{3}$ Menlo College, Hubei, Xiaogan, China \\ ${ }^{4}$ Lesley University, Nanchang, Jiangxi, China \\ ${ }^{*}$ Corresponding author. Email: mabelzhu7398@outlook.com \\ ${ }^{\dagger}$ Those authors contributed equally.
}

\begin{abstract}
Past studies have shown that gender stereotypes from parents and students affect students' own academic performance. However, the effect of teachers' gender-related perspectives on students and its mechanism remains unclear. The purpose of this study is to explore how gender stereotypes of teachers affect students and what kind of influence it has on students. This paper first introduced the definition of the gender stereotype and how to measure it and then analyzed the relationship between gender stereotypes of teachers and students' academic performance. Finally, combined with the literature, the study found that teachers' gender stereotypes would have a negative impact on students' academic performance through these mechanisms: 1) self-concept; 2) competence beliefs and task values. Specifically, the higher students' self-concept, competence beliefs and task values, the better their performance. Thus, when teachers have gender stereotypes, it will affect these factors, and then students' academic performance will be affected. And the paper also puts forward some deficiencies that still exist at present. For example, there are also some hidden influence mechanisms that may have not been taken into account. This requires further research in the future. The findings highlight the need for educators, researchers and policymakers to address gender stereotypes to encourage male and female development in all fields.
\end{abstract}

Keywords: teachers' gender stereotypes, academic performance, negative affect, influencing mechanism

\section{INTRODUCTION}

This paper review hopes to research the impact of teachers on students. According to the Pygmalion effect [1], teachers have a subtle effect on students: the higher expectations teachers have, the better students' performance. Thus, people could see the positive effect of the expectation of teachers on students from the Pygmalion effect, and our team are curious whether teachers only have a positive effect on the student?

According to research, Stereotypes about social groups can influence children's developing beliefs about themselves (self-perceptions) and also influence children's motivation in science, technology, engineering, and math (STEM) [2]. Based on findings published on Statista, in the fields of mathematics and computer science, the ratio of males to females earning doctorate degrees in the United States is about one to three (females to males). In pedagogy, which seems to be more biased towards liberal arts, the proportion of males and females who have obtained Ph.D. degrees is just the opposite [3]. This data surprised us that there are obvious differences in the number of Americans who have achieved academic achievement in different subjects. It is undeniable that boys and girls are indeed different in their innate talents. Girls usually show the internal locus of control, so it is easier to get better marks in Literature for most girls. On the other hand, boys prefer using concentration and getting better marks in mathematics [4]. However, it is hard to believe that only the difference in innate talents will cause huge differences in the academic achievement of American boys and girls.

\subsection{Review of Related Studies}

One study found out that girls taught by teachers who have gender stereotypes for longer than one year 
would negatively behave worse in math subjects and a verbal test, while there were fewer findings on boys due to teachers' transmitting beliefs [5]. Another study has put their purpose on investigating the implication of teacher's gender bias as it would affect girls particularly, on their future choice of subjects as they transfer from middle school to high school. By conducting the study using a comparison of math and science scores and teachers' internal and external feedback on the exam, the researchers find out that there is an influence of teacher's biased beliefs on student's decision making regarding high school course choosing [6]. Other literature points out that the influence of gender stereotypes in shaping biased expectations of and behaviors towards groups are profound, especially in terms of gender [7]. What's more, some longitudinal studies indicated an increasing gender stereotype effect over time [8]. Some studies say gender stereotypes will influence students' perceptions of but behavior in specific subjects, even undermining their enthusiasm [9].

Reviewing the related literature finds that teachers' gender stereotypes play a role in shaping individuals' development, such as school grades, directly. However, we find that the research of influencing mechanisms is not specific and clear enough. Therefore, this paper mainly discusses the mechanism of action systematically and fully from this angle.

\subsection{Purpose of the Study}

In the hope of addressing the issue, there are two questions this study aims to ask: 1) Does teacher's gender stereotypes take an impact on both female and male students on their academic influence? 2) If it does, what kind of factors would get involved in this affecting mechanism?

According to the previous studies, it is likely that sex stereotypes revealed by the teachers would influence how students consider their self-efficacy regarding mathematical subjects [10]. Moreover, teachers tend to believe that girls are less likely to be skilled in math than boys [11]. Another study adding the point that mathematical self-concepts are more likely to be developed in boys [12]. Based on previous studies, it is considered to indicate that there has been a pattern of how female and male students have a clear awareness of what kind of ability they obtain on different subjects.

In addition, gender stereotypes influence how girls specifically reflect themselves as being advanced in mathematical knowledge and having positive motivation or optimism in such a field. The same condition regarding how boys are less likely to think they are good at verbal or art skills [13]. It is being considered that with pre-occupied self-perception of different subjects that they should be advanced, both female and male students would spontaneously form different psychological change thus performed differently in mathematical and other subjects.

This paper will solve the questions that have been mentioned in the early section: 1) Do teacher stereotypes have an impact on students? 2) If so, are there any influencing mechanisms? We introduced the definition of gender stereotypes and treasured the gender stereotypes. Then this paper showed the relationship between the teachers' gender stereotypes and students' academic performance, including 1) what impact 2) factors. Finally, this paper points out the possible limitations of previous studies and then give a conclusion,

\section{GENDER STEREOTYPES}

\subsection{Definition}

Although the stereotype is a cognitive structure that contains the perceiver's knowledge, beliefs, and expectations about some group of human beings [14], the essence of the stereotype are that people generally hold beliefs [15]. And gender stereotypes are defined as "structured sets of beliefs about the personal attributes of men and women [16].

\subsection{Ways to Measure the Gender Stereotypes}

The implicit association test (IAT), a tool developed within social psychology [17], will measure it. The IAT uses the categorization of words on the right or left of a computer to measure the strength of the connection between two concepts, in this case, gender and the science/humanities field. Two sets of stimuli were presented to the teachers [10]. One set included some subjects related to humanities (e.g., reading skills) and scientific fields (e.g., mathematics), and another set included names of male (e.g., David) and female (e.g., Nancy). When words appeared one at a time in the center of the screen, the teachers were asked to categorize them quickly to the left or right, based on the different labels displayed at the top of the screen (e.g., the label "Female" on the left and the label "Male" on the right). If teachers have implicit associations between female and humanities fields, they will do the task faster and easier when they categorize these words on the same side of the screen. A large body of social psychology literature and economic papers provide evidence for the validity of the IAT sores in predicting behaviours and choices [18]. And compared with other measurement tools, IAT has been widely used in some fields of exploring the nature of implicit biases against the out-groups (e.g., gender) because of its reliability and effectiveness [19]. 


\section{THE RELATIONSHIP BETWEEN THE STEREOTYPE OF TEACHER AND STUDENTS' ACADEMIC PERFORMANCE}

\subsection{What impact}

Social identity theory [20] explains the group's influence on individuals when people attribute themselves to a certain group. Academic gender stereotypes of a group do affect students' academic performance. The negative impact of teachers' gender stereotypes on students can also be inferred from this. From a realistic perspective, a study showed that teachers' gender stereotypes of men in the field of reading would have a negative impact on men's reading ability [21]. Coincidentally, a few years later, another experiment involving 54 teachers and 1,358 fifth grade students researched the teachers' expectations of students' reading ability are significantly related to students' reading performance. The gender of the student has positively correlated with the teacher's expectation of the students' reading ability. The teacher's expectation of the girl's reading ability is higher than that of the boy's reading ability [22]. All the above studies show that teachers' stereotypes affect students' performance in reading. However, stereotypes will not only affect students' reading. In mathematics, girls will show signs of deterioration in their academic performance after being taught traditional gender concepts for more than a year [5].

Another study also came up with the idea that teachers would pay more attention to the students they preferred [23]. Adding to the point, a study from Coen found that the differences in teaching interactions would influence students' learning outcomes [24]. Given these preconditions, the gender stereotypes from the teaching context would impact limiting both genders of students regarding their self-perception among other people and their achievement. [25].

As the documented evidence shows, there is existing a direct influence from teacher's gender stereotypes on student's academic performance by indirectly transmitting their gender-biased values, which leaves a potential cue on student's own beliefs. Students would unconsciously take these values into a cognitive thinking process that relatively shapes their motivation to study, which causes changes in academic outcomes.

\subsection{Influence mechanism}

\subsubsection{Self-concept}

Academic self-concept, which includes a person's self-evaluation of the academic field, is formed through experience and interpretation of the environment. It involves a sense of confidence and competence [26]. Findings from the previous studies indicate that the higher the student's academic self-concept, the higher the motivation to invest time and energy in learning activities in the field [27], thus affecting his academic performance. And Gender stereotyping of teachers manifests not only in communication but also in abnormal support for students. When they subscribe to specific gender stereotypes (for example, they think that boys are better at math and girls are better at reading), then they are more likely to influence students' confidence in those areas [28]. Indeed, one study suggests that those at risk of confirming well-known negative stereotypes lower their self-confidence and perform less well in areas where their group's abilities are discriminated against [29]. And teachers who think that boys do better than girls in scientific fields will improve boys' confidence in it. For example, in one study, men's confidence, buoyed by a sense of gender superiority, leads them to perform better than women on "masculine" tasks, such as mathematics [30]. In contrast, the relationship between task values and grades is negative when they are not coupled with high competence beliefs [31]. That is, enhancing students' task values without competence beliefs will [32].

\subsubsection{Competence beliefs and task values}

Other factors mediate the relationships between teachers' gender stereotypes and students' academic performance, among which competence beliefs and task values are regarded as a mediate role [33]. According to the expectancy-value theory, expectancy concerns the beliefs of competence and self-efficacy. Value means the extent of how they believe their task is significant, worthwhile and interesting [34]. Research shows that students who hold higher competence beliefs achieve better outcomes than their unlucky counterparts who are exposed to lower expectations of competence [35]. Also, the research [36] about the direct and indirect relationship between mathematics stereotypes and competence beliefs and grades shows that when these female students internalize the stereotypes, they believe their gender is less competent in math aspects than they predicted to get lower grades. Besides, the relationship between task values and grades is negative when the high competence beliefs are controlled [31]. This means that only enhance students' task values but low competence beliefs will have a pernicious effect on school grades [32]. Specifically, teachers' gender stereotypes influence students' competence beliefs and task values and thus affect their academic performance [27].

One research has indicated that a teacher would have influenced the student's own beliefs by entering his/her values of gender roles during the classroom [29]. In their study, students have the tendency to obtain and 
absorb these beliefs as teachers have a certain amount of authority; thus, what teacher says cause a significance on how female students or male students perceive themselves on different subjects. Another research draws upon this statement as it emphasized that some of the teachers who behold traditional values about gender roles would implement their values by ignoring questions from female students, giving various feedback or directly put more attention on teaching male students because they relatively think those female students would not take academic outcomes as potential as male students do, since in the future female students would not have the circumstances to give knowledge in use [37].

\section{LIMITATION}

The published studies so far have some limitations. While the studies take into account key variables such as self-concept, there are still some hard-to-control variables that are not taken into accounts, such as qualifications and teaching experience and students' effort level and learning ability.

Besides, although current studies have found the relationship between gender stereotypes and academic performance, they have not measured the influencing mechanisms such as students' self-concept.

Therefore, future experimental studies can be considered to improve experimental details according to the problems mentioned above and improve the credibility of conclusions by controlling experimental influencing factors more comprehensively.

\section{CONCLUSION}

The findings of this paper provide new insights into the role of teacher gender stereotypes on students. This study finds the relationship between teachers' gender stereotypes and students' academic performance. These studies show that when gender stereotypes exist, it impacts students' self-concept, competence beliefs and task values, and then these affecting mechanisms will influence students' academic performance. About the theoretical and practical implications, there will be a significant relationship between how female and male students perceived themselves as having advanced talent on different subjects, based on teacher's gender stereotypes and how they practically well performed in the target subject. To address gender stereotypes regarding one being smart or relatively intellectual whereas another is not, this research focuses more on the double sides as the study equally draw on females and males. Speaking of stereotyping behaviors on one gender, by decelerating the otherness and fortifying the similarities, this study adds a more intermediate lens among the existing discoveries. Through this research, the research is dedicated to revealing to the educators what their misconceptions and behaviors could contribute to students' future development. It is also a great way to awaken teachers to dispelling gender stereotypes and giving boys and girls the same hope in class and exams. Thus, students will have the courage and no psychological burden to face the knowledge in all academic fields.

\section{REFERENCES}

[1] Rosenthal, R., \& Jacobson, L. (Eds.). (1968). Pygmalion in the classroom: Teacher expectations and student intellectual development. New York, NY: Holt.

[2] Master, A. (2021). Gender stereotypes influence children's stem motivation. Child Development Perspectives, 15(3),203-210. https://doi.org/10.1111/cdep.12424

[3] NCSES. (December 1, 2020). Number of doctorate recipients in the United States in 2019, by gender and field of study [Graph]. In Statista. Retrieved August 22, 2021, from https://www-statistacom.menlocollege.idm.oclc.org/statistics/240141/u s-doctorate-recipients-by-gender-and-field-ofstudy/

[4] Ghazvini, S. D., \& Khajehpour, M. (2011). Gender differences in factors affecting academic performance of high school students. Procedia - Social and Behavioral Sciences, 15, 1040-1045.

https://doi.org/10.1016/j.sbspro.2011.03.236

[5] Alan, S., Ertac, S., \& Mumcu, I. (2018). Gender stereotypes in the classroom and effects on achievement. Review of Economics and Statistics, 100(5), 876-890.

[6] Lavy, V., \& Sand, E. (2018). On the origins of gender gaps in human capital: Short- and long-term consequences of teachers' biases. Journal of Public Economics, $\quad$ 167, 263-279. doi: 10.1016/j.jpubeco.2018.09.007

[7] Schneider, D. J. (2004). The psychology of stereotyping. New York, NY: Guilford Press.

[8] Archambault, I., Eccles, J. S. ,\& Vida, M. N. (2010). Ability self-concept sand subjective value in literacy: Joint trajectories from grades 1 through 12. Journal of Educational Psychology, 102, 804816.

[9] Kiefer, A. K., \& Sekaquaptewa, D. (2007). Implicit stereotypes and women's math performance: How implicit gender-math stereotypes influence women's susceptibility to stereotype threat. Journal 
of Experimental Social Psychology, 8, 611615. https://doi.org/10.1016/j.jesp.2006.08.004

[10] Carlana, M. (2019). Implicit stereotypes: Evidence from teachers' gender bias. The Quarterly Journal of Economics, 134, 1163-1224.

[11] Tiedemann, J. (2002). Teachers' gender stereotypes as determinants of teacher perceptions in elementary school mathematics, Educational Studies in Mathematics, 50, 49-62.

[12] Eccles, J., Wigfield, A., Harold, R. D., \& Blumenfeld, P. (1993). Age and gender differences in children's self-and task perceptions during elementary school. Child development, 64(3), 830847.

[13] Marsh, H. W. (1989). Sex differences in the development of verbal and mathematics constricts: The high school and beyond study. American Educational Research Journal, 26, 191-225.

[14] Hamilton, D. L., \& Trolier, T. K. (1986). Stereotypes and stereotyping: An overview of the cognitive approach.

[15] Baron, A. S., Schmader, T., Cvencek, D., \& Meltzoff, A. N. (2014). The gendered self-concept: How implicit gender stereotypes and attitudes shape self-definition. Gender and development, 109-132.

[16] Ashmore, R. D., \& Del Boca, F. K. (1979). Sex stereotypes and implicit personality theory: Toward a cognitive-social psychological conceptualization. Sex Roles, 219-248.

[17] Greenwald, A. G., McGhee, D. E., \& Schwartz, J. L. (1998). Measuring individual differences in implicit cognition: The implicit association test. Journal of Personality and Social Psychology, $74,1464-1480$.

[18] Nosek, B. A., Smyth, F. L., Hansen, J. J., Devos, T., Lindner, N. M., Ranganath, K. A., ... \& Banaji, M. R. (2007). Pervasiveness and correlates of implicit attitudes and stereotypes. European Review of Social Psychology, 18, 36-88.

[19] Devine, P. G. (2001). Implicit prejudice and stereotyping: How automatic are they? Introduction to the special section. Journal of personality and social psychology, 81, 757.

[20] Ellemers, N., \& Haslam, S. A. (2011). Social identity theory. Handbook of theories of social psychology, 2(2011), 379-98.

[21] Retelsdorf, J., Schwartz, K., \& Asbrock, F. (2015). "Michael can't read!" Teachers' gender stereotypes and boys' reading self-concept. Journal of Educational Psychology, 107(1), 186.

[22] Muntoni, F., \& Retelsdorf, J. (2018). Genderspecific teacher expectations in reading-The role of teachers' gender stereotypes.Contemporary Educational Psychology, 54, 212-220.

[23] Rosenthal, R. (1994). Interpersonal expectancy effects: A 30-year perspective. Current Directions in Psychological Science, 3, 176-179.

[24] Caruthers, L. (2005). Classroom interactions and achievement. Mid-Atlantic Research for Education \& Learning. Retrieved from: http://www.mcrel.org/ products/noteworthy/noteworthy/loycec.asp

[25] Shelley S.S. (2000). The relationship among teacher expectations, teacher attitudes toward the TAAS, and student achievement. Denton, TX: University of North Texas. Retrieved from: http://digital.library.unt.edu/ark:/67531/metadc269 1/ m2/1/high_res_d/Dissertation.pdf

[26] Ertl, B., Luttenberger, S., \& Paechter, M. (2017). The impact of gender stereotypes on the selfconcept of female students in STEM subjects with an under-representation of females. Frontiers in psychology, 8, 703.

[27] Eccles, J. S., Adler, T. F., Futterman, R., Goff, S. B., Kaczala, C. M., Meece, J. L., et al. (1983). Expectancies, values, and academic behaviors. In J. T. Spence (Ed.), Achievement and achievement motivation (pp. 75-146). San Francisco, CA: Freeman.

[28] Bhanot, R., \& Jovanovic, J. (2005). Do parents' academic gender stereotypes influence whether they intrude on their children's homework? Sex roles, 52, 597-607.

[29] Spencer, S. J., Steele, C. M., \& Quinn, D. M. (1999). Stereotype threat and women's math performance. Journal of experimental social psychology, 35, 4-28.

[30] Kamas, L., \& Preston, A. (2012). Are women really less willing to compete than men? gender stereotypes, confidence, and social preferences. Mimeo Haverford College.

[31] Lancaster, B. P. (1999). Defining and interpreting suppressor effects: Advantages and limitations. Paper presented at the Southwest Educational Research Association, San Antonio, TX.

[32] Plante, I., O’ Keefe, P. A., \& Théorêt, M. (2013). The relation between achievement goal and expectancy-value theories in predicting achievement-related outcomes: A test of four 
theoretical conceptions. Motivation \& Emotion, 37(1), 65 - 78. http://dx.doi.org/10.1007/s11031012-9282-9.

[33] Eccles, J. S. (1994). Understanding women's educational and occupational choices: Applying the Eccles et al. model of achievement-related choices. Psychology of Women Quarterly, 18(4), 585-609.

[34] Eccles, J. S., \& Wigfield, A. (2002). Motivational beliefs, values, and goals. Annual Review of Psychology, 53(1), 109-132.

[35] Bleeker, M. M., \& Jacobs, J. E. (2004). Achievement in math and science: Do mothers' beliefs matter 12 years later? Journal of Educational Psychology, 96(1), 97 - 109.

[36] Bonnot, V., \& Croizet, J.-C. (2007). Stereotype internalization and women's math performance: The role of interference in working memory. Journal of Experimental Social Psychology, 43(6), $857-866$.

[37] Sadker, M., \& Sadker, D. (2010). Failing at fairness: How America's schools cheat girls. Simon and Schuster. 